\title{
Influência da dinâmica urbana e a ocupação de áreas inundáveis no bairro de Magoanine-A (Moçambique): uma reflexão para o zoneamento ambiental
}

\author{
Bernardino José Bernardo \\ Departamento de Geografia e Ambiente e Desenvolvimento, \\ Universidade Pedagógica-Maputo, Moçambique
}

DOI: https://doi.org/10.31492/2184-2043.RILP2018.35/pp.61-68

\begin{abstract}
Resumo
Introdução: Estudiosos apontam que o uso mais notório e que mais altera os processos morfodinâmicos é o urbano, e que muitas vezes está associado à decorrência de desastres naturais (inundações, cheias, erosão). $\mathrm{O}$ presente artigo visa analisar o processo de ocupação de áreas inundáveis no bairro de Magoanine-A. O estudo apoiou-se na abordagem qualitativa alicerçada nos seguintes métodos e técnicas: revisão bibliográfica e cartográfica, observação directa, questionário, análise e síntese. Diante disto, foi possível perceber que o processo de apropriação do relevo local por habitações intensifica os processos morfodinâmicos ocasionando de forma cíclica inundações nos relevos mais baixos. O estudo sugere a alteração do uso habitacional para o uso ecológico.
\end{abstract}

Palavras-chave: inundação; ocupação; urbano; zoneamento ambiental.

\begin{abstract}
Introduction: Scholars point out that the most noticeable and most disturbing use of morphodynamic processes is urban use, which is often associated with natural disasters (floods, erosion). This article aims to analyze the process of occupation of flooded areas in the district of Magoanine-A. The study was based on the qualitative approach based on the following methods and techniques: bibliographic and cartography review, direct observation, questionnaire, analysis and synthesis. In view of this, it was possible to perceive that the process of appropriation of the local relief by dwellings intensifies the morphodynamic processes causing cyclical floods in the lower reliefs. The study suggests the change in housing use for ecological use.
\end{abstract}

Keywords: environmental zoning; flood; morphodynamic processes; occupation; urban.

\section{Contextualização}

Moçambique é um país que se localiza na África Oriental com cerca 23\% de população urbana. No entanto, as estatísticas mostram que até 2030 cerca de $50 \%$ da população moçambicana estará a residir nas cidades (Serra, 2012). Este crescimento urbano ocorre com intensidade diferentes nas várias regiões e províncias do país, com a cidade de Maputo (capital do país) a registar a taxa mais elevada.

A urbanização decorre na cidade de Maputo de forma espontânea, sem autorizações ou planificação, levando as populações a ocupar espaços cuja morfologia (depressões e vertentes) lhes confere vulnerabilidade e sensibilidade em relação a determinados riscos ambientais como inundações e erosão.

A história da urbanização de Maputo mostra que está, esteve, sempre associada à disposição da morfologia local, como se pode notar na seguinte proposição: 
O processo de urbanização da cidade de Maputo iniciou na parte baixa da cidade que corresponde à linha paralela da costa e tendo posteriormente alastrado para as partes relativamente altas mantendo a orientação do traçado paralelo à costa, e que muitas vezes determinou a secagem dos pântanos envolventes e adaptação à topografia propondo a extensão do núcleo antigo ao nível do mar mediante a ocupação de uma área de menor declive, que estabelece a ligação com a zona de planalto entre os 40 e os 50 metros (Melo, 2013)

Todavia, o processo da urbanização actual da cidade de Maputo caracteriza-se por ser horizontal e desordenado. Onde Serra (2012, p.12) afirma que: "bairros inteiros têm surgido nas cidades moçambicanas subitamente, sem qualquer estudo prévio sobre o impacto de assentamentos humanos nas áreas visadas".

Alguns bairros da cidade de Maputo, como é o caso do bairro de Magoanine-A, apresentam em algumas áreas uma morfologia dunar, formando autênticas depressões susceptíveis aos riscos geomorfológicos, tais como a inundação e a erosão, e nos últimos anos assiste-se a uma forte ocupação destes espaços para a construção de habitações.

Dados estatísticos publicados pelo CMCM (2010) (Conselho Municipal da Cidade de Maputo) apontam que o bairro de Magoanine-A está contido num dos distritos urbanos que mais cresce nos últimos anos (Kamubukwane). Nesta óptica, o autor constatou que a urbanização deste bairro ocorre segundo a lógica da orientação do relevo e sem nenhuma planificação ou correcção do mesmo, o que agrava em parte alguns riscos naturais, tais como a inundação e a erosão, tendo repercussões socioeconómicas como a destruição de infra-estruturas. Esta situação é reforçada por Ventura, (S/d, p.3) ao referir que, "o processo de urbanização é precedido pela destruição do coberto vegetal e movimentação de terras, com o consequente incremento da erosão, desvio, canalização ou mesmo supressão de linhas de água, concorrendo para a desordem da rede hidrográfica". A urbanização de génese ilegal é ainda mais gravosa, dado que, em regra, ocupa áreas com fortes condicionantes biofísicas. Esta mudança, é responsável pela progressiva impermeabilização e consequente aumento da proporção de água precipitada que alimenta o escoamento superficial. Nas pequenas sub-bacias, a ocupação em contínuo artificializa o escoamento e agrava os riscos a jusante. Nos leitos de cheia, as construções para além de sujeitas aos efeitos das inundações, transformam-se em obstáculos à progressão das águas, provocando a subida do seu nível a montante e um aumento da velocidade e do potencial destrutivo da corrente.

Em vários países, nomeadamente nos EUA, crescem as críticas às intervenções estruturais (reassentamentos para o nosso caso ou construção de sistemas de drenagem), pelos seus impactos no ambiente, apostando em soluções que permitam a recuperação das funções ecológicas dos leitos de cheia. O controle sobre a 
ocupação do território é feito com a aplicação de medidas indirectas como o zonamento em função do risco de inundação associado a uma política de seguros. Esta é baseada em prémios de seguro diferenciados em função do risco da área em que se incluem os edifícios e actividades a segurar. Esta política apela a uma responsabilização individual e contribui para um ordenamento que tem em consideração o grau de risco inerente a cada área Ventura (S/d, p. 12).

\section{Metodologia}

Para a realização da presente pesquisa optámos pela metodologia de abordagem qualitativa, apoiada num conjunto de métodos e técnicas de pesquisa científica, tais como: revisão bibliográfica - onde foi possível cruzar vários autores que abordam; observação directa - onde foi possível observar as formas de ocupação do bairro (traçado das ruas em relação ao relevo); a observação indirecta - esta técnica de pesquisa foi bastante útil na leitura e análise das cartas topográficas da área de estudo, de forma a perceber a disposição do relevo, esta técnica permitiu também fazer análise da dinâmica da ocupação do bairro de Magoanine - A, (2005-2015) a partir da interpretação das imagens de satélites da área de nos períodos compreendidos entre 2005 e 2015; o método cartográfico - para proceder com a localização geográfica da área em estudo assim como para a elaboração do mapa hipsométrico e o de curvas de níveis da área; o questionário - auxiliou na busca de informações inerentes as causas da ocupação da área de estudo bem como a colher informações sobre os efeitos socioambientais. No total foram inquiridas 150 famílias, residentes nas várias configurações morfológicas da área de estudo (depressão e encosta dunar).

\section{Localização da área de estudo}

O bairro de Magoanine-A localiza-se na Cidade de Maputo, no distrito Urbano Kamubukwane. Os 12 quarteirões que perfazem a área do nosso estudo têm uma área de cerca de $6 \mathrm{~km}^{2}$. A área em estudo conta com os seguintes limites: a norte pelo Bairro de Magoanine B e C, a sul pela Avenida Lurdes Mutola, a este pela Avenida Milagre Mabote e a oeste da Rua da Escola da Primária de Magoanine-A (figura 1).

\section{Características morfológicas da área de estudo}

No que tange a nossa área de estudo e de acordo com os dados contidos na publicação do Ministério de Recursos Minerais e Energia, (s/d, folha N²532D3) o bairro de Magoanine-A é coberto por depósitos intradunares, com a predominância de areias brancas que ocupam as depressões intradunares resultantes da destruição de dunas circundantes. 
Figura 1. Localização geográfica da área de estudo. Fonte: Bernardo (2016)

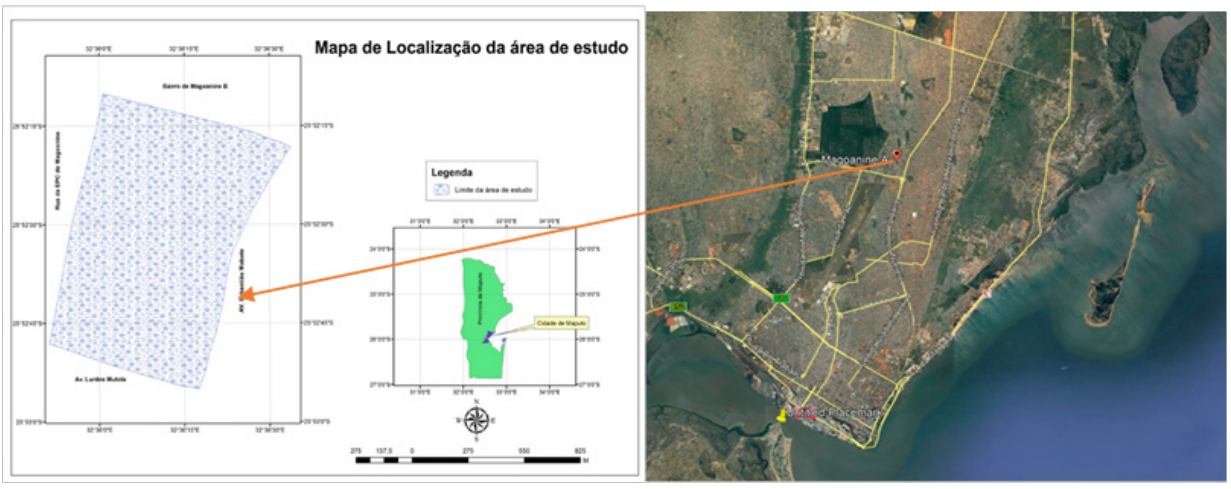

Do ponto de vista topográfico, de acordo com a Direcção Nacional de Geografia e Cadastro (1989, Folha $\left.n^{\circ} 1190\right)$, a área em estudo predominam altitudes que variam entre 34 metros a 57 metros. As altitudes menores coincidem com as áreas mais deprimidas e com a baixa de Xivunguana que corta perpendicularmente o bairro em estudo, enquanto as altitudes médias coincidem com as encostas e as mais acentuadas constituem as cristas das dunas circundantes (figura 2 e 3 ).

Figura 2 e 3. Relevo da área de estudo e perfil do relevo da área de estudo. Fonte: Bernardo (2016)
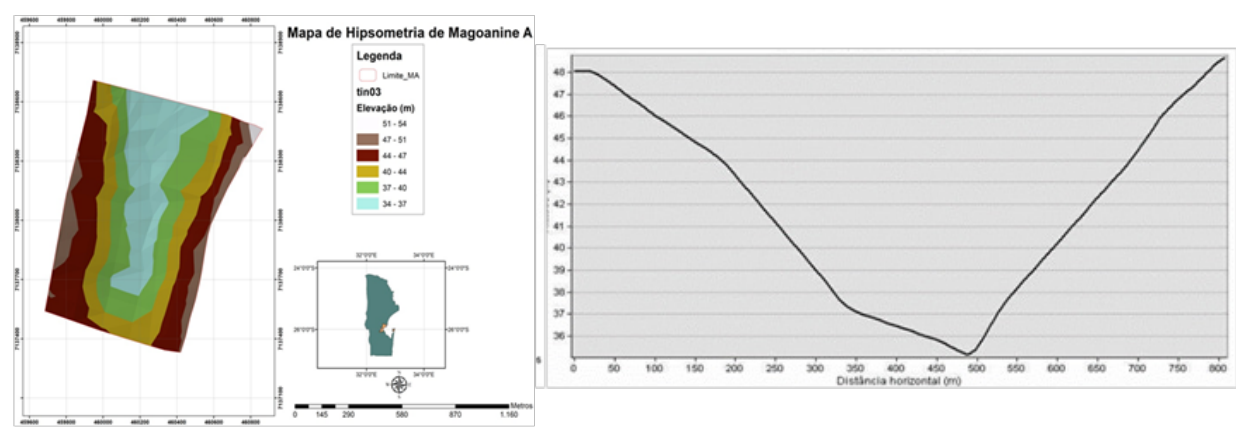

\section{Dinâmica urbana do bairro de Magoanine-A e a ocupação de áreas inundáveis}

O uso mais notório do relevo do bairro de Magoanine-A é a urbanização. Desta maneira, Lattes (1990) considera que o processo de urbanização é o crescimento numérico da proporção da população que vive nas cidades. Os dados do Censo de 1997 apontam que a população do bairro de Magoanine-A era de cerca de 11.900 habitantes, e no censo de 2007 o bairro de Magoanine-A contava com cerca de 120.163 habitantes (INE, 2007). Estes dados revelam um aumento da população neste bairro o que se traduziu em parte pela forte ocupação dos espaços devolutos 
existentes no bairro. Esta ocupação se traduziu pela expansão do tecido urbano. Importa secundar que em 2005 o bairro apresentava uma forte concentração de habitações na área de relevo alto e tempos depois esta concentração começou a expandir com certa intensidade para zona baixa. Isto é, as populações foram habitando espaços deprimidos, este cenário alterou os processos morfodinâmicos locais, visto que, houve maior compactação dos solos e consequentemente a redução da capacidade de infiltração, tornando a área baixa vulnerável as inundações (figura 4 e 5).

Figura 4 e 5. Dinâmica da ocupação da área de estudo. Fonte: Google Earth, Outubro de 2017
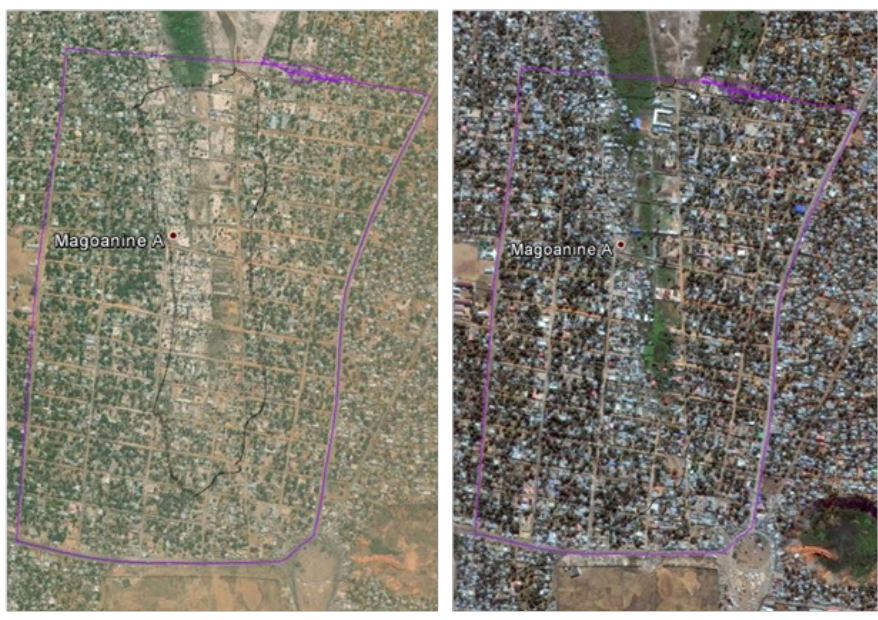

Os resultados do questionário, aponta que avanço da ocupação da área baixa deveu-se á vários factores, como: A forte demanda procura dos espaços para habitação (30\%), preços relativamente baixos para aquisição do espaço - área deprimida (40\%), a localização estratégica do bairro em relação ao centro urbano $(20 \%)$ e por fim a existência de equipamentos sociais (escolas, hospitais, vias de acesso, energia eléctrica, etc) (figura 6). Importa referir que, os resultados do questionário apontam que a área baixa (Inundável) é na sua maior parte ocupada pelos emigrantes. Isto é, habitantes que vem de outro ponto do país (figura 7).

As novas de ocupação trouxeram novos arranjos espaciais no bairro, como por exemplo a abertura de novas ruas em direcção a área baixa e a forte utilização das mesmas, o que se traduziu em compactação dos solos. As alterações nos usos dos solos associado a forma como as ruas foram traçadas, isto é, cortando as curvas de níveis do relevo local acelerou bastante a vulnerabilidade da área baixa as inundações (figura 8 e figura 9). 
Figura 6 e 7. Causas da ocupação de áreas inundáveis. Proveniência e tempo de residência. Fonte: Bernardo (2016).
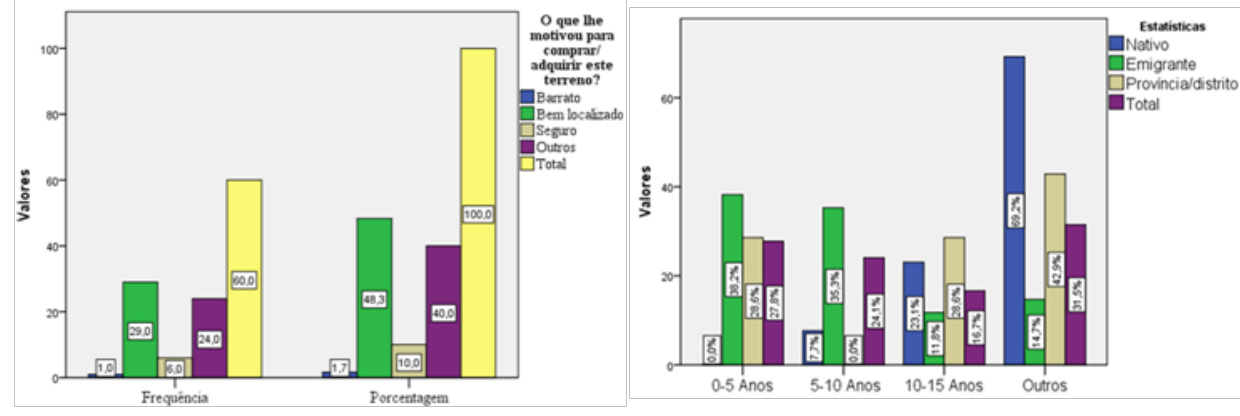

Figura 8 e 9. Disposição do relevo e dinâmica da ocupação do bairro. Fonte: Bernardo (2016).

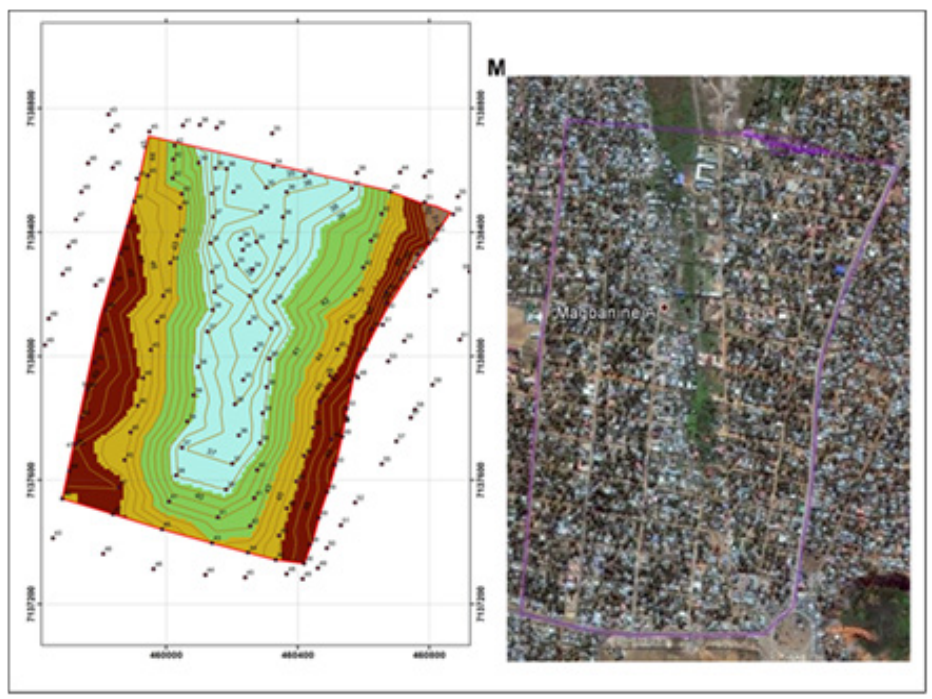

A dinâmica da ocupação trouxe novos arranjos espaciais no bairro, como por exemplo a abertura de novas ruas em direcção à área baixa e a forte utilização das mesmas, o que se traduziu na compactação dos solos. As alterações nos usos dos solos associado à forma como as ruas foram traçadas, isto é, cortando as curvas de níveis do relevo local acelerou bastante a vulnerabilidade da área baixa às inundações.

\section{Estratégias para a redução dos efeitos socioambientais da inundação}

Diante da vulnerabilidade do bairro em relação as inundações, o estudo sugere a transformação do uso habitacional desta área para o uso ecológico, de forma a reduzir os danos causados pelas inundações bem como a redução da 
intensidade da mesma. $\mathrm{O}$ uso ecológico na área inundável poderá permitir a colecta das águas drenadas pelas ruas bem como o desenvolvimento da biodiversidade e pode-se construir parques para diversos fins. O estudo também recomenda a redefinição do processo de urbanização do bairro no que tange a orientação das ruas e a construção de um sistema de colecta de águas pluviais dentro dos quintais das áreas altas de modo a reduzir o escoamento superficial nas ruas consequentemente a redução da erosão ao longo das vertentes e inundação na área baixa.

\section{Considerações finais}

Depois da análise feita em torno do tema, o estudo concluiu que o processo de urbanização que caracteriza o bairro de Magoanine-A, altera significativamente os processos morfodinâmicos locais, dinamizando em grande medida fluxos de escoamento pluvial para zona baixa, conferindo - lhe deste modo à ocorrência de forma cíclica das inundações. Diante deste cenário, o estudo sugere a mudança do uso habitacional para ecológico ou agrícola, pois estes usos adequam-se as particularidades morfológicas da área de estudo. Convêm referir que a história do território demonstra que o uso agrícola sempre caracterizou esta depressão intradunar.

\section{Referências}

Amaral, R., et. al. (2012). Desastres Naturais - conhecer para prevenir. $2^{\mathrm{a}}$ edição, São Paulo.

Bernardo, J B. (2016). Os efeitos sócio-ambientais da Urbanização: Caso das depressões e encostas dunares no bairro de Magoanine-A (2005-2015), Dissertação de Mestrado, Universidade Pedagogica.

Araújo, M. (1998). Geografia dos povoamentos. Uma análise geográfica dos assentamentos humanos rurais e urbanos, UEM, Maputo.

Conselho Municipal da Cidade de Maputo. (2010). Perfil estatístico do município 2007-2008, Maputo.

Direcção Nacional de Geografia e Cadastro (1989, Folha n¹190).

Lattes, A. (1990). Distribuição Espacial, Urbanização e Migração. Dinâmicas Demográfica e Processos económicos, sociais e culturais. Série população e Desenvolvimento, $\mathrm{N}^{\circ} 2$, Maputo.

Mello, Vanessa de Pacheco. (2013). Urbanismo português na cidade de Maputo: passado, presente e futuro. Revista Brasileira de Gestão Urbana (Brazilian Journal of Urban Management), (5)1, 71-88. jan.jjun.

Ministério de Recursos Minerais e Energia. (S/d). Maputo - folha №2532D3.

Serra, C. (2012). Da problemática ambiental à mudança. Editora Escolar, Maputo. 
Suguio, Kenitiro. (2010). Geologia do Quaternário e mudanças ambientais. Oficina de textos, São Paulo.

Ventura, José, \& Pereira, Margarida. (2004). As Áreas Inundáveis em meio urbano. A abordagem dos instrumentos de planeamento territorial, VII Congresso da Água, Lisboa.

Xavier, B., \& Carmynie, B. (2012). Modificações ambientais provocadas pela urbanização. Disponível em www.proamb.com.br (consultado no dia 12-12-2015).

Data receção: 24/02/2017

Data aprovação: 16/03/2018 